\title{
Working scheme for safe management of construction and demolition wastes containing hazardous substances
}

\author{
N. Quaranta, M. Caligaris, H. López \& M. Unsen \\ Universidad Tecnológica Nacional, F. R. San Nicolás, Argentina
}

\begin{abstract}
Wastes from construction and demolition (C\&D) are mainly composed of inert materials. A small proportion of C\&D wastes contain substances which make them hazardous, for example, those wastes containing asbestos, mineral fibres, additives, some paints and resins, among others.

On the other hand, in the manufacturing of several products used in the construction industry many hazardous substances are utilized. In most cases these materials are relatively safe while being used, but they become dangerous when they are broken, spilled or released in some way.

There are other wastes groups which are not hazardous by themselves, but they can suffer reactions, producing toxic substances. These groups include, for example, some plastics or treated woods, which can emit toxic gases when they are burnt for energetic profit.

In this work a scheme is presented for the safe management of construction and demolition wastes containing hazardous substances, starting from an inventory of hazardous wastes. This scheme takes into account different stages: i) selective extraction avoiding the mixture with no hazardous wastes, ii) characterization of hazardous substances contained in C\&D, iii) feasibility evaluation of the reuse or recycle of the analyzed material and, iv) adequate treatment either for recycling or for safe final disposal.

This constitutes the first step in the way of obtaining proper norms in this area, absent nowadays from the local regulations.
\end{abstract}

Keywords: hazardous wastes, construction, toxic substances. 


\section{Introduction}

The demolition, repair or alteration of buildings located in an urban environment is characterized by the generation of a significant volume of residues, which are usually known as "debris". These residues form the category known as construction and demolition waste (C\&D). The environmental problem posed by the C\&D wastes is derived not only from the increasing volume of his generation, sometimes exceeding that of waste from households, but also from its treatment.

Several alternatives to reuse the C\&D have been proposed, transforming them into raw material of the same civil construction industry, for example, to replace a percentage of materials used in concrete [1-5]. Also C\&D wastes management models have been studied [6,7], including life cycle analysis of buildings [8], and new procedures for selective extraction and reuse [9].

A high percentage of C\&D waste is inert. However, a small proportion of them contain hazardous waste. Taking into account its main characteristics and the hazardous pollutants that can presumably contain, the properties set by the EPA (Environmental Protection Agency) can be mentioned when it focuses on construction and demolition. Thus, waste should be considered hazardous if it exhibits any of the following characteristics [10]:

$\checkmark$ Ignitability. Ignitable wastes can create fires under certain conditions, are spontaneously combustible, or have a flash point less than $60^{\circ} \mathrm{C}\left(140^{\circ} \mathrm{F}\right)$. Examples include waste oils and used solvents.

$\checkmark$ Corrosivity. Corrosive wastes are acids or bases ( $\mathrm{pH}$ less than or equal to 2 , or greater than or equal to 12.5) that are capable of corroding metal containers, such as storage tanks, drums, and barrels. C\&D wastes do no contain, generally, corrosive wastes.

$\checkmark \quad$ Reactivity. Reactive wastes are unstable under normal conditions. They can cause explosions, toxic fumes, gases, or vapors when heated or mixed with water. C\&D wastes do no contain, generally, reactivity wastes.

$\checkmark$ Toxicity. Toxic wastes are harmful or fatal when ingested or absorbed. When toxic wastes are land disposed, contaminated liquid may leach from the waste and pollute ground water. C\&D wastes contain materials with these characteristics, for example, asphalt and pitch, and lead pipes.

The so-called inert waste can have various origins: excavations and earthworks, those arising from road and infrastructure, a mixture of construction debris or demolition of buildings and rejects or breaks in the manufacture of parts and construction elements.

Those wastes containing dangerous substances in mixtures or separate fractions of construction and demolition debris (including excavated soil from contaminated sites) are considered hazardous wastes. Only a small part of the C\&D wastes are considered as hazardous waste, they consist of materials, mixtures, drainage mud, land or rocks that are contaminated with hazardous substances or contain substances such as mercury, lead, polychlorinated phenyls compounds, asbestos, etc. 
Among the hazardous waste found in the C\&D ones it can be specifically mentioned: waste of paint, varnish, solvents, sealants, resins, adhesives, lubricants and fillers, containers with above products, treated wood, including old furniture, straps, or floors, items containing asbestos such as some types of old tiles or insulation, paint containing lead or lead welding, mercury containing products and other items with hazardous components that can not be separated.

The environmental impact produced when these hazardous waste are deposited along with the inert ones in unprotected landfills, has been studied by Roussat and collaborators, determining which pollutants can be transported to soil or water [11].

In this work a scheme for safe management of construction and demolition wastes containing hazardous substances is presented, starting from an inventory of hazardous wastes. This scheme takes into account different stages: i) selective extraction avoiding the mixture with no hazardous wastes, ii) characterization of hazardous substances contained in $\mathrm{C} \& \mathrm{D}$, iii) feasibility evaluation of the reuse or recycle of the analyzed material and, iv) adequate treatment either for recycling or for safe final disposal. The inventory of hazardous wastes used for preparing this scheme was presented in a previous work [12].

This work was carried out within the PROCQMA project, of the National Technological University [13]. This integrative project aims to establish a clear identification of the C\&D wastes and process wastes (PW) in the different regions of Argentina and set specific criteria for feasibility of reusing them in construction industry. The feasibility analysis is based on the knowledge of the national map of the PW and C\&D wastes and advanced characterization of them from the technological point of view. The final expected goal is to generate a list of technical specifications for the use of PW and C\&D wastes in the construction, setting new standards and quality control strategies.

In relation to the $C \& D$ wastes, they can be classified in a simple way into the following types: reusable, recyclable at building site and recyclable offsite.

1)The reusable $\mathrm{C} \& \mathrm{D}$ wastes consist of materials that can be reused as withdrawal of the construction, with simple cleaning and recovery treatments, and to provide similar service, for example, doors, windows, sheets entire profiles iron.

2)The C\&D wastes recyclable at building sites are those wastes that can be processed and arranged in the building, with potential for reuse in the same place. For example: concrete, masonry, tiles, and asphalt mixtures, among others.

3) The C\&D wastes recyclable offsite are those which by their nature can be recycled at specific plants, mainly for their recovery value and the interest shown by agents or recyclers. These wastes are, for example, wood, plastics, metals, etc.

The larger part of C\&D wastes that can be potentially dangerous because of their characteristics and that have some chance of recovery is within the types of recyclables offsite.

Figure 1 shows photographs illustrating the separation on site under this classification. 


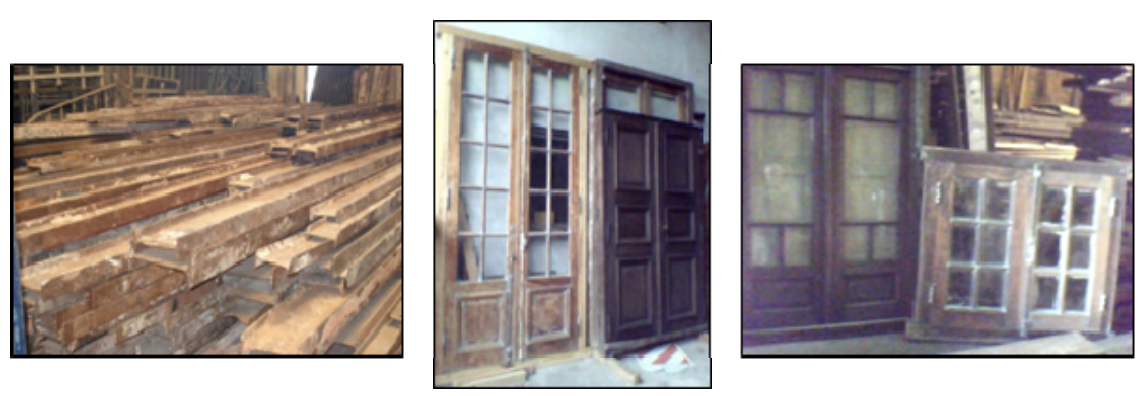

Reusable C\&D wastes.

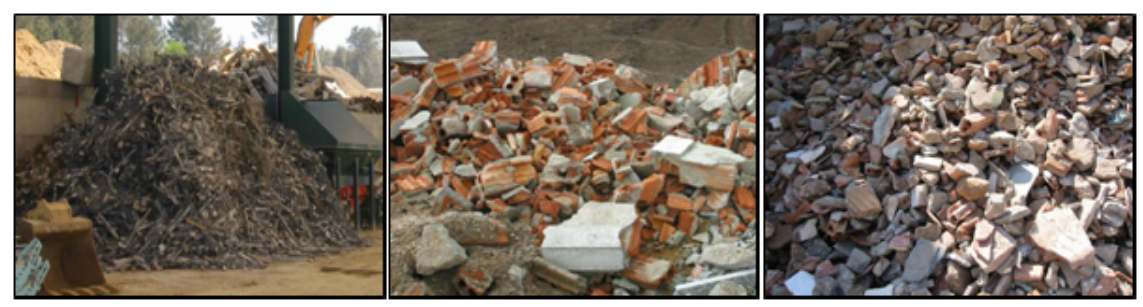

$C \& D$ wastes recyclable at building site.

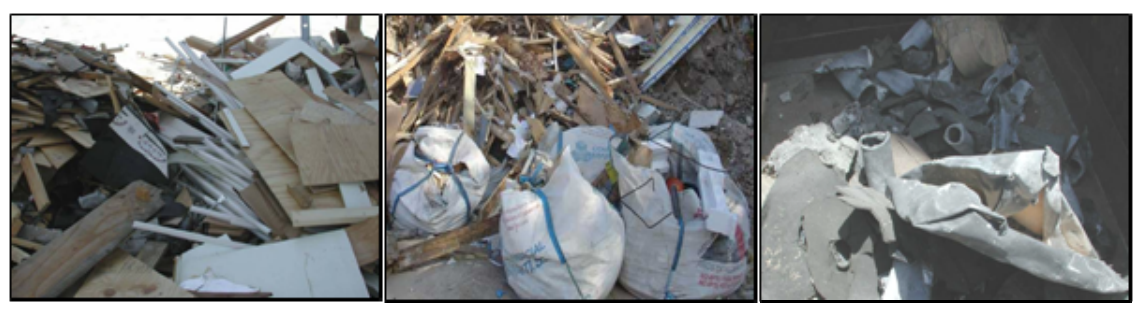

C\&D wastes recyclable offsite.

Figure 1: $\quad$ C\&D wastes classification.

In the case of demolition, repair or renovation, an obligation has to be established to make an inventory of hazardous waste to be generated by providing selective extraction, avoiding mixing with non-hazardous waste and properly defining if its destination is the reuse, recycling or safe disposal.

\section{Selective demolition}

The selective demolition is defined as that resulting from the use of techniques that outcomes greater environmental care and the possibility of reusing materials, components and facilities. 
The demolition process is arranged opposite to the construction process, in the following phases: removal of wastes and the non fixed elements of decoration, orderly taking apart timber, sanitary and heating appliances, air conditioning, plumbing, electricity, etc., external elements, false ceilings and recoverable lining, removal of roofs, decks and interior divisions, controlled demolition of the structure by cutting the different elements.

Wastes must be correctly separated and stored in suitable containers, made of materials that are not affected by the residual and resistant to manipulation. These containers must be identified with a label and be placed in a well ventilated area and protected from the sun and rain, as well as separated from heat sources or flames, and so that the products that can react with each other are not together. Wastes must be listed in a register.

When moving outside, both hazardous waste and their containers, and materials contaminated with these products should be delivered to be processed by authorized agents. Welding products, bitumen-based sealants and asbestos, protective and creosote, germicides, antioxidants, paints and varnishes, other chemicals (corrosion, driers, fungicides, insecticides, solvents, acids, abrasives, detergents, etc.), among others, should be treated as hazardous.

\section{Main hazardous contaminants present in C\&D wastes}

In order to establish the main hazardous contaminants present in $C \& D$ wastes, in a first stage the following substances are selected:

-Aluminum: Aluminum is a silvery white metal after its purification from mineral bauxite and cryolite. Its strength, lightness in weight, and resistance to corrosion makes it suitable for a wide variety of applications, which can be mentioned as important in relation to their presence in the C\&D wastes, its usefulness in the manufacture of doors and windows in the construction industry.

The most common damage to the human being is produced by exposure to aluminum powder. This causes a disease called pulmonary fibrosis, which is thickening and scarring of lung tissue in contact with the particles. Aluminum may promote the development of respiratory diseases, emphysema, and renal diseases by intoxication.

-Arsenic: The toxicity of arsenic, a chemical element present in nature, depends on their form of combination, being the inorganic most toxic than the organic. The most harmful effects on the population as consequences of exposure are lung cancer by inhalation and skin cancer by ingestion. The EPA puts arsenic among the four chemical elements with the greatest potential to cause cancer, within a list of 54 classified.

In C\&D wastes, arsenic can be found in chromate copper arsenate (CCA). CCA has been used to protect wood used in construction since the 70s. Nowadays, the CCA is no longer used because of potential health problems caused by contact, and the availability of wood preservatives that do not contain arsenic. However, due to their long lifetime, CCA-treated wood can be part of $\mathrm{C} \& \mathrm{D}$ wastes for many years. 
-Asbestos: This material is composed of various natural mineral compounds in the form of small fibers, which by their aerodynamic characteristics are distinctive in being airborne for a long time traveling long distances.

The contact with people is through inhalation of these fibers being installed in the throat, retained in the lung, or continuing their way to the digestive system. It can cause lung or intestine cancer development, being asbestosis the most common condition, defined as lung and membrane envelopes fibrosis.

The asbestos-containing materials were widely used in buildings as insulation or for being fire resistant. Asbestos are found in the tiles and vinyl floor coatings, repairing compounds and textured paints, in some roofing, in stoves and furnaces insulation, pipe insulation, walls and ceilings, in some roofing tiles and wall finishes.

-Asphalt: The asphalt is a substance from brown to black, with a very particular strong smelling. According to the temperature and chemical composition, it may occur as a viscous or solid material. It consists of numerous heavy and light hydrocarbons. It is found in the environment due to its use as pavement, roof and pipe coating, and as component of adhesives and industrial insulation.

Its major toxicity is when the material is hot-worked, since asphalt emits many potentially hazardous products (light aromatic hydrocarbons). Experiences in laboratory with animals have shown that persistent contact with skin can cause cancer and that prolonged exposure to its fumes can cause respiratory problems.

Within the C\&D wastes, a significant amount of discards containing asphalt is present. It can be seen in the dismantling of roofs, as protective coatings under wall panels, in pipes and wiring, etc.

-Cadmium: Cadmium is a silver-colored metal resistant to corrosion, that has been used for over 50 years in a variety of products and industrial processes, such as galvanized metal products, pigments in paints and plastics, rechargeable batteries, preservative of plastics, alloys and special welding, varnishes and paints.

People can be in contact with various possible sources of cadmium, such as combustion processes, fertilizers, snuff, etc. In C\&D wastes, cadmium may be present in plastics, painted products, and $\mathrm{Ni}-\mathrm{Cd}$ batteries.

The toxicity in humans is related to the development of lung, heart, kidney and liver diseases, through inhalation and ingestion.

-CFC (Chlorofluorocarbons): These compounds have been widely used as cooling agents, due to their low toxicity, low flammability, high chemical stability and low cost. Later, they have been used as solvents and aerosol propellants in the manufacture of foams.

These compounds are considered of low direct toxicity to humans, although with prolonged exposure nervous system depression, palpitations and disorders of pregnancy have been detected. The main problems are environmental in nature since CFC cause a slow deterioration of the ozone layer, which decreases the ability of atmospheric layer protection against ultraviolet radiation.

For the particular case of C\&D wastes, these compounds can be found in wall panels and insulating foams. Many of them are manufactured with $\mathrm{CFC}$, and 
most of these substances are trapped in bubbles of foam, which give precisely the great insulating properties to these products.

-Creosote: Creosote is an oily liquid, dense, combustible, brown and pungent. It is a mixture of chemicals obtained from the distillation of tar from wood or coal whose composition varies according to the source (may contain varying amounts of phenol, cresols, creosol, benzene derivatives, etc.).

Its main use is as a wood preservative, for its waterproofing action, antiseptic, disinfectant, germicide and weather protection. Its widest use is in railway sleepers and lighting columns, but it is also found in wood for construction (roofing, fences, veneers, etc.).

The toxicity in humans occurs by direct contact with the liquid or by aspiration of the fumes. It can cause progressive burns, skin ulceration and eye lesions. Acute systematic effects include headache, vomiting and breathing difficulties. The EPA classifies it as a possible carcinogen.

Due to the type of products that may contain creosote, since its use is not regulated yet, large quantities of these compounds may be found, primarily in wood fences, roof ties and sleepers.

-Lead: Lead is one of the six principal pollutants for which EPA has imposed regulations on air, water and soil due to its toxicity. The metal in the organism behaves similarly to calcium, and accumulates in the bones.

In the construction industry, lead was widely used mainly in pipes and junctions for water transport and distribution systems, both in industrial and domestic buildings. It had also widespread use as a base for pigments in paints. The lead paint is no longer used, but many old buildings have these paintings on their walls, windows or doors. As well as being dangerous to people working in demolition, debris containing these paintings may be directed to the soil and potentially contaminates the water. Studies have been conducted to quantify the amount of lead in dust from demolition, in order to estimate the exposure of people living in the vicinity [14-15]. Leaching from lead paint debris in landfills have also been tested [16].

The C\&D wastes generated nowadays in the demolition works are from products that were manufactured many years ago. Lead can be found in discarding of pipes, lead pipes and connections used in the distribution of water and debris with lead-based paints, among others.

-Mercury: Mercury has particular features that make it interesting for use in many devices, it is liquid at room temperature, dense and electrically conductive. The toxicity of the metal is known and also its vapors and most of its compounds, which can be fatal to all life. Some inorganic compounds containing it are used in paints as anti-mould agents, and although not toxic in this form, they can be converted by the action of certain bacteria to mercury methylate form. This compound can be transported in water accumulating in fish and it can also be readily absorbed by humans through the consumption of fish.

There are many elements commonly found in C\&D wastes containing mercury: fluorescent, mercury vapor, high pressure sodium and neon lamps, smoke detectors, emergency lighting systems, barometers, cathode ray tubes, thermostats, thermometers, etc. 
-Mineral fibers (other than asbestos): The mineral fibers, commonly known as fiberglass, glass wool, rock wool or mineral powders, are primarily used in thermal insulation materials in buildings. Generally consist of coiled fibers of different lengths attached to a thick dense material as paper or fabric. Bonded with resin are used as rigid structures.

These materials do not involve risks themselves, except when they are exposed with the possibility that the loose fibers contact the skin or can be inhaled by people. In these cases it can lead to irritation or itchy skin and eyes, and breathing difficulties.

The presence of mineral fibers in the C\&D wastes must be detected by the time to exclude the case of asbestos materials, mineral fibers with much greater toxicity as explained above.

-PCB (polychlorinated biphenyls) and PBB (polybrominated biphenyls): $\mathrm{PCB}$ is a number of compounds containing a variable number of chlorine atoms in its composition, with toxicities that vary with their number and their position in the molecular structure. Commercial formulas contain between 40 and 70 compounds of this type. Polybrominated biphenyls (PBB) are different from PCB because bromine atoms join the basic structure. Both have a low flammability and similar applications.

PCB and PBB were widely used for insulation and cool electrical components such as transformers and capacitors due to their little flammability. These products may contain them without environmental risk. However, there is great diffusion in the environment for its use in plasticizers, coloring matter, dyes, adhesives, and wood protectors.

All these compounds are generally considered highly toxic. Their appearance is variable and may occur as oily liquids, crystalline solids, or non-crystalline hard resins. They are not soluble in water, and are very resistant to degradation by light or heat, although some of them react with ultraviolet light to produce new compounds even more toxic than the originals.

\section{Scheme for safe management of C\&D wastes}

As regards the selected contaminant substances, the following considerations have to be taking into account at the moment to reuse, recycle or dispose C\&D wastes which contain them.

-Aluminum: Aluminum products can be reused without major risks, with purposes similar to the original ones. The procedures for reuse must consider safety precautions in the stages of cutting and polishing because fine dust is generated that is hazardous to health, as has been stated.

-Arsenic: There is growing concern about the disposal of wood treated with preservatives with $\mathrm{Cr}, \mathrm{Cu}$ and $\mathrm{As}$ basis, due to the high concentrations of toxic inorganic contaminants present and the large volumes of wood waste currently being generated. In many countries, including the United States, the wood treated with chromate copper arsenate and other $\mathrm{Cu}$-based preservatives are exempt from the designation of dangerous, regardless of their characteristics. So, 
common methods for dealing with this type of waste are burning and disposal in landfills. These waste management practices can result in environmental contamination with toxic pollutants. An alternative to deal with this problem is the chemical extraction with bioleaching with fungi [17].

Discarding wood treated with chromate copper arsenate can be reused if surface coatings are removed and new treatments are carried out for protection. Special care is required during the recovery process of the wood base, aimed at the protection of workers from the solvents used and the fine dust generated during the process. Then the safe disposal of generated waste such as paint, lacquer, sawdust, among others, containing arsenic in the form of CCA, as the main pollutant is required.

-Asbestos: The EPA, the U.S. agency responsible for regulating the use of asbestos in the environment and manufactured goods, has prohibit the use of these compounds into new products, placing it among the first in the list of hazardous air pollutants. The same occurs in Japan and most European countries. However a large amount of materials containing asbestos still exists in various constructions. So guidelines should also be established for disposal when demolitions occur, determining its not reuse.

The disposal in landfills never diminishes the danger of this residue. In Japan, for example, treatment of melting $\left(\mathrm{T}>1000^{\circ} \mathrm{C}\right)$ is the only method allowed as intermediate treatment, but alternative methods have been proposed to decompose asbestos at lower temperatures [18].

-Asphalt: In the case of asphalt wastes whose origin is pavements, is already usual to reuse them for the same service, namely the construction of new roads or repairing existing ones, by crushing and milling at room temperature and their incorporation to fresh mixtures on site. Last generation of industrial machinery for re-pave use these materials incorporating them automatically.

The reuse or recycling of wastes containing asphalt from any application source must be made by milling at room temperature, and the addition of other inert materials. The exposure to high temperatures must be avoided because asphalt discards release hydrocarbons into the environment. The emission of fine particles into the environment during the crushing and grinding processes should also be prevented otherwise it is considered an air pollutant in the form of particulate matter.

-Cadmium: The identification and selection of products that contain this element is recommended for demolition processes and fractional separation of the C\&D wastes. Controlled incineration with emission control method is the suggested procedure. In the particular case of $\mathrm{Ni}-\mathrm{Cd}$ batteries, procedures for recycling and recovery of metals are available.

-CFC: A recent study in the United States estimates that approximately 6000 tons per year of insulating foam waste are disposed in C\&D landfills in California. This equates to 600 tons of CFC [19].

These products containing CFC can be reused for the same insulation purpose, being important during the process of dismantling and packaging to keep the foam structure intact, and make as few cuts as possible. If the grinding 
of these materials is needed, it is recommended to use retention chambers with gas and fine particulate matter generated in this procedure extraction.

-Creosote: In the case of defining the reuse of creosote-treated wood at least two surface protective treatments are recommended, such as sealants and coatings varnishes or lacquers, which do not allow direct contact in later use. It is also indicated in these cases not to burn wood treated with creosote for energetic profit, because the gas flowing from the combustion process is extremely irritating and harmful to health and the environment.

-Lead: The reuse of lead pipes in water distribution is not recommended. Their disposal must be carried out with care to avoid contact with water that can carry the lead into soils and groundwater.

Those reusable items that have lead paint should be treated as: i) if the original paint is intact, the surfaces must be coated with lead-free paint or varnish before recycling, and ii) if the original paint must be removed, special care must be taken with wearing or removing it, because breathable particles with significant lead content can be generated.

It is recommended to those working with wastes containing lead paint, to protect their health, following certain guidelines: collect the chips, particles, dust and masonry paint in plastic bags or suitable containers (covered) until its safe disposal, not smoking, eating or drinking in settings while working with paint, and no longer wear clothing that has been covered with dust from these paintings.

-Mercury: While there are many items that contain mercury within the C\&D wastes, most of them can be easily identified and selected. Recovery of these items is recommended not only because it prevents contamination of soil and water close to the demolition, but to avoid being sent to landfills in uncontrolled conditions. It is important to keep the mercury isolated and to send these products to appropriate facilities for treatment or recovery or appropriate disposal sites.

-Mineral fibers (other than asbestos): Mineral fibers present in C\&D wastes can be reused with extreme care in handling them and when reusing is safe, without the presence of dust or microscopic fibers on the resulting environment. Masks and gloves should be worn during removal and adequacy for reuse. The mineral fibers themselves are not regulated, so that risk levels are those available for particulate matter.

$-\boldsymbol{P C B}$ and $\boldsymbol{B P B}$ : If products such as transformers containing $\mathrm{PCB}$ and $\mathrm{BPB}$ are present in the $C \& D$ wastes, the spill must be prevented, and must be safely disposed, although it is recommended as an effective method for disposal, incineration at high temperatures $\left(1100{ }^{\circ} \mathrm{C}\right.$ to $\left.1700{ }^{\circ} \mathrm{C}\right)$ with excess oxygen, achieving complete destruction. However, some very toxic byproducts such as dioxins and furans can be formed during this process, which must be retained with chemical filters. Therefore also flying and sediment ashes remaining in the filters and chimneys that extract these compounds must be further processed.

A recent study in Norway suggests that the painting of structures built during the 1950-1970 period may be the most important source of PCB in the urban environment [20]. To safely identify building materials that contain PCB a series 
of samples of materials such as paint, mortar, plaster, and sealant, must be analyzed before renovation or demolition of a building.

A Spanish version related to this work was presented in "II Simposio Iberoamericano de Ingeniería de Residuos", held in Barranquilla, Colombia in September 2009.

\section{Conclusions}

The C\&D wastes, mainly composed of masonry products, wood, asphalt, plaster, metals, plastics and isolations, have traditionally been regarded as inert. At present some C\&D wastes presumed inert waste are considered hazardous or potentially hazardous, and only in some cases the requirements for removal and handling are regulated.

In the short term, it is important that even in the event that the removal of waste from construction and/or demolition activities, and the feasibility of reuse or disposal, are not controlled, to generate awareness and commitment in builders and homeowners to take into account the possibility of finding among these C\&D wastes, presence of hazardous substances, and the availability of technical tools to enable recycling, reuse or safe disposal.

In the medium and long term, regulation by a statement of technical specifications aimed at those involved in the activities of C\&D seems to be the most appropriate way to achieve maximum safety in handling C\&D wastes when they contain hazardous substances. This statement must contain a list of potentially hazardous waste, the steps for a selective withdrawal to avoid mixing with non-hazardous waste, simple techniques for characterization of hazardous substances contained in the C\&D wastes, workable processes for reuse or recycling of the material analyzed, and proper treatment prior to a safe disposal if necessary.

\section{References}

[1] Debieba F., Kenaib S. The use of coarse and fine crushed bricks as aggregate in concrete, Construction and Building Materials, 22(5), pp. 886-893, 2008.

[2] Naceri A., Haminaa M. C. Use of waste brick as a partial replacement of cement in mortar, Waste Management, 29(8), pp. 2378-2384, 2009.

[3] Corinaldesi V. Mechanical behavior of masonry assemblages manufactured with recycled-aggregate mortars, Cement and Concrete Composites, 31 [7], pp. 505-510, 2009.

[4] Cachim P.B, Mechanical properties of brick aggregate concrete, Construction and Building Materials, 23(3), pp.1292-1297, 2009.

[5] Padminia A.K., Ramamurthy K., Mathewsa M.S. Influence of parent concrete on the properties of recycled aggregate concrete, Construction and Building Materials, 23(2), pp. 829-836, 2009. 
[6] Roussat N., Dujet C., Méhu J. Choosing a sustainable demolition waste management strategy using multicriteria decision analysis, Waste Management, 29(1), pp. 12-20, 2009.

[7] Solís Guzmán, J., Marrero M., Montes Delgado M.V., Ramírez de Arellano A. A Spanish model for quantification and management of construction waste, Waste Management, 29 [9], pp. 2542-2548, 2009.

[8] Blengini G.A. Life cycle of buildings, demolition and recycling potential: A case study in Turin, Italy, Building and Environment, 44(2), pp. 319-330, 2009.

[9] Mulder E., de Jong T.P.R., Feenstra L. Closed Cycle Construction: An integrated process for the separation and reuse of C\&D waste, Waste Management, 27(10), pp. 1408-1415, 2007.

[10] http:/www.epa.gov/osw/hazard/wastetypes/characteristic.htm

[11] Roussat N., Méhua J., Abdelghafour M., Brula P. Leaching behaviour of hazardous demolition waste, Waste Management, 28(11), pp. 2032-2040, 2008.

[12] Quaranta N., Caligaris M., López H., Unsen M. Metodología para RCD cuando contienen sustancias peligrosas, Actas del $5^{\circ}$ Encuentro del Proyecto Integrador PROCQMA, 2007.

[13] Botasso H.G., Fensel E.A. Proyecto para el uso sistemático de residuos de construcción, demolición y procesos industriales, Actas del IV Congreso Internacional de Metalurgia y Materiales (Conamet-Sam), 2004.

[14] Farfel M.R., Orlova A.O., Lees P.S.J., Rohde C., Ashley P.J., Chisolm J.J. A study of urban housing demolition as a source of lead in ambient dust on sidewalks, streets, and alleys, Environmental Research, 99(2), pp. 204-213, 2005.

[15] Mucha A.P., Stites N., Evens A., MacRoy P.M., Persky V.W., Jacobs D.E. Lead dustfall from demolition of scattered site family housing: Developing a sampling methodology, Environmental Research, 29(2), pp. 143-148, 2009.

[16] Wadanambi L., Dubey B., Townsend T. The leaching of lead from leadbased paint in landfill environments, Journal of Hazardous Materials, 57(1), pp. 194-200, 2008.

[17] Sierra-Alvarez R. Removal of copper, chromium and arsenic from preservative-treated wood by chemical extraction-fungal bioleaching, Waste management, 29(6), pp. 1885-1891, 2009.

[18] Yanagisawa K., Kozawa T., Onda A., Kanazawa M., Shinohara J., Takanami T., Shiraishi M. A novel decomposition technique of friable asbestos by $\mathrm{CHClF}_{2}$-decomposed acidic gas, Journal of Hazardous Materials, 163(2-3), pp. 593-599, 2009.

[19] Kjeldsen P. What do C\&D waste and end-of-life refrigerators have in common? Waste Management, 28(11), pp. 2031, 2008.

[20] Jartun M., Tore Ottesen R., Steinnes E., Volden T. Painted surfaces Important sources of polychlorinated biphenyls (PCBs) contamination to the urban and marine environment, Environmental Pollution, 157(1), pp. 295-302, 2009. 